Article

\title{
Clinical Study for Silk Mat Application into Extraction Socket: A Split-Mouth, Randomized Clinical Trial
}

\author{
Ju-Won Kim ${ }^{1,+}$, You-Young Jo ${ }^{2,+}$, Jwa-Young Kim ${ }^{3} \mathbb{C}$, Ji-hyeon $\mathrm{Oh}^{4} \mathbb{C}$, Byoung-Eun Yang ${ }^{1, *}$ and \\ Seong-Gon Kim ${ }^{4} *$ (D) \\ 1 Department of Oral and Maxillofacial Surgery, Sacred Heart Hospital, College of Medicine, Hallym \\ University, Anyang 14068, Korea; kjw9199@hanmail.net \\ 2 Sericultural and Apicultural Materials Division, National Academy of Agricultural Science, Rural \\ Development Administration, Wanju-gun 55365, Korea; yyjo@korea.kr \\ 3 Department of Oral and Maxillofacial Surgery, Kangnam Sacred Heart Hospital, Hallym University, \\ Seoul 07441, Korea; jwayoung@hanmail.net \\ 4 Department of Oral and Maxillofacial Surgery, College of Dentistry, Gangneung-Wonju National University, \\ Gangneung 25457, Korea; haruna348@naver.com \\ * Correspondence: omsyang@gmail.com (B.-E.Y.); kimsg@gwnu.ac.kr (S.-G.K.); Fax: +82-33-641-2477 (S.-G.K.) \\ + Both authors are equally contributed.
}

Received: 11 December 2018; Accepted: 19 March 2019; Published: 22 March 2019

\begin{abstract}
Silk mat originates from the cocoon of the silkworm and is prepared by a simple method. The material has been used for guided bone regeneration (GBR) in animal models. In this study, the silk mat used for a clinical application was compared with a commercially available membrane for GBR. A prospective split-mouth, randomized clinical trial was conducted with 25 patients who had bilaterally impacted lower third molars. High-density polytetrafluoroethylene (dPTFE) membrane or silk mat was applied in the extraction socket randomly. Probing depth (PD), clinical attachment level (CAL), and bone gain (BG) were measured at the time of extraction (T0) and then at three months (T1) and six months after extraction (T2). There was no missing case. GBR with silk mat was non-inferior to GBR with dPTFE for PD reduction at T1 and T2 ( $\left.p_{\text {non-inferiority }}<0.001\right)$. PD and CAL were significantly decreased at $\mathrm{T} 1$ and $\mathrm{T} 2$ when compared with those at $\mathrm{T} 0$ in both membrane groups $(p<0.001)$. BG at T2 was $3.61 \pm 3.33 \mathrm{~mm}$ and $3.56 \pm 3.30 \mathrm{~mm}$ in the silk mat group and dPTFE group, respectively. There was no significant complication from the use of silk mat for the patients. The results for patients undergoing GBR with silk mat for third-molar surgery were non-inferior to GBR with dPTFE for PD reduction.
\end{abstract}

Keywords: guided bone regeneration; silk mat; polytetrafluoroethylene; probing depth; bone gain

\section{Introduction}

The presence of a third molar is common in human populations; however, third molars in the mandible are often impacted in the bone [1]. An impacted third molar is often a source of infection in the adjacent second molar [2], and an odontogenic cyst or malocclusion may be observed with an impacted third molar [3,4]. Accordingly, many oral and maxillofacial surgeons have recommended surgical removal as a preventive measure [2,5]. The extraction socket is generally healed by bone formation, but the level of bony healing is dependent on many clinical variables [6,7]. The most important factor is the age of the patient at the time of extraction [8]. Early removal of the third molar is advised because younger patients have a higher probability of uneventful healing after extraction [9]. 
Incomplete bony healing results in periodontal pocket formation on the distal surface of the second molar $[8,10]$.

In young patients (age $<25)$, removal of the mandibular third molar can improve periodontal health significantly [11,12]. Patients older than 26 years with periodontal pathology in the distal surface of the second molar and a horizontal/mesioangular impacted third molar need regenerative therapy $[13,14]$. Most mandibular third molars for surgical extraction have a mesial inclination and are in contact with the adjacent second molar [5]. Periodontal pathology is found in $48 \%$ of second molars after surgical removal of the adjacent mandibular third molar [10]. Probing depth is more than $7 \mathrm{~mm}$ in $43.3 \%$ of adjacent second molars after surgical extraction of the mandibular third molar $[8,15]$. To prevent periodontal pocket formation and promote uneventful bony healing, grafting with biomaterials can be considered $[16,17]$. Autogenous bone is generally considered the gold standard for bone graft, and synthetic materials such as hydroxyapatite are considered an alternative for the reconstruction of the extraction socket [18]. Ridge preservation materials have been used as filling materials for the extraction socket. They are collagen-based material and have shown positive effects for the preservation of the alveolar bone. However, there have been few reports on their application in the mandibular third-molar area.

For the preservation of the alveolar bone, a guided bone regeneration (GBR) technique is a useful method [10,19]. GBR is beneficial for patients aged 26 years or older who have a horizontally impacted third molar and a probing depth (PD) of $5 \mathrm{~mm}$ or greater in the distal surface of the adjacent second molar [20]. For a successful GBR technique, the selection of membrane is important [6]. The membrane for a GBR technique can be classified as comprising either biodegradable or non-degradable materials. An expanded polytetrafluoroethylene (ePTFE) membrane is non-degradable material whereas a collagen membrane is biodegradable $[10,19]$. A comparative study of their application into the mandibular third-molar area has shown that there is no statistically significant difference between the ePTFE group and the collagen group in preventing a periodontal pocket [19]. However, a high rate of postoperative infection has been reported from ePTFE membrane after membrane exposure [21]. High-density PTFE (dPTFE) has been developed for an open-membrane technique and shown less postoperative infection after membrane exposure [22].

The idea for the development of a GBR membrane by using natural silkworm cocoons has been suggested in some recent publications [23,24]. A silkworm cocoon is composed of several layers, and each layer can be separated by peeling [24,25]. Silk mat from silkworm cocoons is mainly composed of fibroin and sericin; the middle layer of the silkworm cocoon shows better bone regeneration properties than other layers of the silkworm cocoon $[25,26]$. The difference in bone regeneration according to layers is explained by the difference of protein composition [25]. Silk mat from the middle-cocoon portion shows bone regeneration similar to that seen when using collagen membrane [27]. GBR membrane using silk protein can be produced only by silk fibroin protein after a degumming process [28]. Silk fibroin degrades slowly; this function is connected to its long-term stability [28]. As silk mat contains silk fibroin as a component, it serves as a barrier membrane for GBR technique [26,27]. The tensile strength of silk mat is superior to that of collagen membrane in both dry and wet conditions $[26,27]$. Although most studies of silk protein-based biomaterials have shown impressive results in cellular or animal experiments, there have been no studies of materials that have resulted in clinical trials.

The purpose of this study was to compare the probing depth (PD) reduction in the dPTFE membrane group with that of the silk mat group in the mandibular third-molar defect. For a split-mouth randomized clinical trial, patients with bilateral, horizontally impacted mandibular third molars were enrolled. In the same patients, both types of membrane were applied on each side and compared. 


\section{Patients and Methods}

\subsection{Trial Design and Registration}

This study was designed as a split-mouth model in the same patient. The null hypothesis was that the primary outcome for silk membrane was inferior to that for commercially available PTFE membrane. The same patients received both types of membranes, and the results were evaluated by the primary outcome. Participants were recruited over 12 months and met the following inclusion criteria. Written informed consents were received from all participants. This study was approved by the Korean Food and Drug Administration (SPENSER-TS101, approved on 27 November 2015), and the institutional review board of Hallym Medical Center approved this study (IRB No. 2016-S016). The clinical trial was submitted to the WHO International Clinical Trial Registry Platform, registered on 14 March 2016 (KCT0003004).

\subsection{Study Population and Eligibility Criteria}

The inclusion criteria were (1) patients with bilateral, fully horizontal or mesioangular impacted, mandibular third molars; (2) American Society of Anesthesiologists (ASA) physical status I or II; (3) 20 to $<40$ years old; (4) presenting minimum $3 \mathrm{~mm}$ bony defect in the distal surface of the mandibular second molar and minimum $5 \mathrm{~mm}$ periodontal pocket depth in the distal surface of the mandibular second molar at the time of extraction; and (5) patient's signed informed consent form. The exclusion criteria were (1) age $<20$ years or $>40$ years, (2) patients with partially impacted mandibular third molar, (3) smokers, (4) patients with any systemic disease, (5) patients receiving irradiation in the head and neck area, (6) patients with malignant cancer history, (7) patients with any oral mucosal disease, and (8) patients with poor oral hygiene. If the applied membrane was exposed before its surgical removal, that case was also excluded. Allowed collateral treatments were (1) maintenance therapy for oral hygiene and (2) antibiotic prescription for preventive purposes. Disallowed collateral treatments were (1) any bone graft into the distal surface of the mandibular second molar and (2) additional periodontal therapy for the distal surface of the mandibular second molar. The sample number was set at 25. For comparative purposes, commercially available dPTFE membrane (CYTOPLAST ${ }^{\circledR}$, Osteogenics Biomedical, Lubbock, TX, USA) was used. The silk mats were gifted from Spencer biomedical technology (Seoul, Korea).

\subsection{Randomization, Allocation Concealment, and Blinding}

The application of the membranes was done by a double-blinded, randomized method. Computer-generated random numbers were used for simple randomization. A random number was generated and allocated to the patient via software. The patients who received random numbers between 0 and 4 received a silk mat on the left side and a dPTFE on the right side. The patients who received random numbers between 5 and 9 received a silk mat on the right side and a dPTFE on the left side. Before finishing the clinical trials, neither patients nor the examiner knew which membrane was applied to which side. The allocated position of each membrane was communicated to the operator and recorded separately by care providers.

\subsection{Sample Size}

To calculate the required sample size, the non-inferiority limit was determined by comparing the primary outcome of PTFE in previous reports [29] with that of placebo in previous reports [30]. The lower limit of confidence interval for PTFE was calculated at $4.0 \mathrm{~mm}$ and the upper limit of that for placebo was calculated at $1.2 \mathrm{~mm}$. Accordingly, the non-inferiority limit was set at $2.8 \mathrm{~mm}$. For the calculation of the sample size, the significance level and power were set at 5\% and 90\%, respectively [31]. The standard deviation of outcome was set as in previous reports [29]. If there was no difference between treatments, 40 samples would be required to be $90 \%$ sure that the lower limit of a one-sided, $95 \%$ confidence interval (CI) would be above the non-inferiority limit of -2.8 . 
The required sample size was calculated by an online program [32] and required a sample of 20 per group. Considering a missing rate, the required sample size for each group was determined to be 25 .

\subsection{Measures}

\subsubsection{Primary Outcome Measure}

The amount of PD reduction was used as the primary outcome and measured as the distance from the free gingival margin to the bottom of the pocket (Figure 1A). The recordings were done at three points of the second molar distal surface (distobuccal, distal, and distolingual). The average value of the three recordings was used for evaluation. PD was recorded at the time of surgery (T0), at three months (T1), and six months (T2) after extraction. For the comparison of PD between groups, a reduced amount of PD at T2 was used for the evaluation of non-inferiority.

(A)

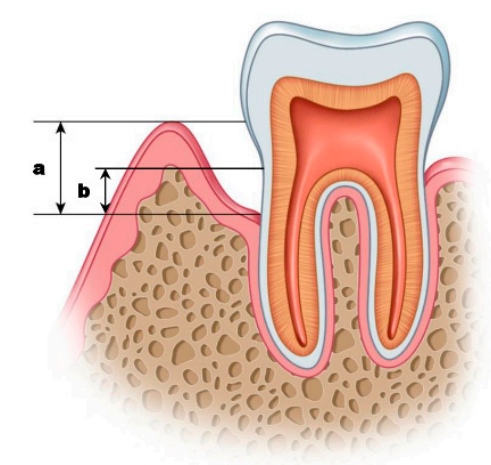

(B)

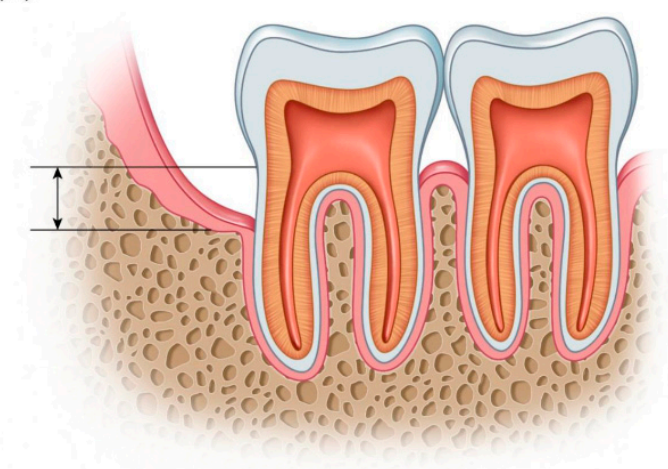

Figure 1. Schematic illustration for measurements. (A) Pocket depth is defined as the distance between the free gingival margin and the bottom of the periodontal pocket (indicated as (a)). Clinical attachment level is defined as the distance between the cementoenamel junction and the bottom of the periodontal pocket (indicated as (b)). (B) The amount of bony defect was defined by the distance between the cement-oenamel junction of the second molar and the bottom of the bony defect in the distal surface of the second molar.

\subsubsection{Additional Measures}

The clinical attachment level (CAL) was recorded in the distal surface of the mandibular second molar in a similar manner to PD measurement (Figure 1A). Cone-beam computerized tomography (CBCT) scans were taken at T0, T1, and T2 to evaluate bony healing. To compare bone gain (BG) between groups, the amount of bony defect was measured on the digital image, using image analysis software (Figure 1B). The amount of bony defect was defined as the distance between the cementoenamel junction of the second molar and the bottom of the bony defect on the distal surface of the second molar. A reduced amount of bony defect at T1 or T2 meant BG in the distal surface of the second molar. At each follow-up, the healing status was evaluated, and the presence of an adverse reaction, including inflammatory reaction or membrane exposure, was checked.

\subsection{Interventions}

The surgical extraction was performed under local anesthesia. After mucosal incision, the periosteum was elevated and the impacted teeth were exposed by rotary instruments. Teeth were removed by resection, and both mandibular third molars were removed. A dPTFE or a silk mat was then applied on the bony defect in each side. The wounds were closed with 3-0 nylon to avoid potential membrane exposure. Antiseptic application and irrigation were performend one day after extraction. Suture was removed one week after extraction. All patients received antibiotics (amoxicillin, $250 \mathrm{mg}$ ) and analgesics 
(aceclofenac, $100 \mathrm{mg}$ ) every $12 \mathrm{~h}$ for five days. Both membranes were removed six weeks after extraction, as indicated in previous reports [33].

\subsection{Statistical Analysis}

To evaluate the non-inferiority of the primary outcome, a two-sample $t$-test for non-inferiority was done using NCSS 12.0.11 (NCSS, Kaysville, UT, USA). Subsequent statistical analysis was done by SPSS 13.0 (SPSS Inc., Chicago, IL, USA). The difference in other measures between groups at the same observation point was evaluated by independent-sample $t$-test. An analysis of variance was used in the comparison of measurements at each time interval in the same group. For the post hoc test, Bonferroni's method was used. The level of significance was set at $p<0.05$.

\section{Results}

\subsection{Summary of Clinical Trial}

The sample recruitment and follow-up was done between 7 March 2016 and 14 July 2017. For each group, there was no missing case after randomization. The number of participants included in each analysis was 25 , and the analysis was performed according to the original assigned groups. Complications associated with the membrane application, such as membrane exposure and associated infection, were not observed. Postoperative temporary gingival swelling appeared in four patients who received membranes. One instance of swelling in a patient was due to excessive alcohol consumption. Two patients had poor oral hygiene. One patient underwent a long operation time because of a deeply seated tooth. Any complication potentially caused by the silk mat application was not reported.

\subsection{Non-Inferiority Test for Primary Outcome}

In terms of the primary endpoint of the trial, mean PD reduction at T1 was $5.72 \pm 1.48 \mathrm{~mm}$ with silk mat versus $6.37 \pm 1.92 \mathrm{~mm}$ with dPTFE (mean difference $-0.65 \mathrm{~mm}$, lower limit of one-sided $97.5 \%$ confidence limit (CI): $-1.63 \mathrm{~mm}$, pre-specified margin of non-inferiority $-2.8 \mathrm{~mm}$, $\left.p_{\text {non-inferiority }}<0.001\right)$. In patients undergoing GBR with a silk mat for third-molar surgery, the results were non-inferior to GBR with dPTFE for PD reduction at T1 (Figure 2A).

(A)

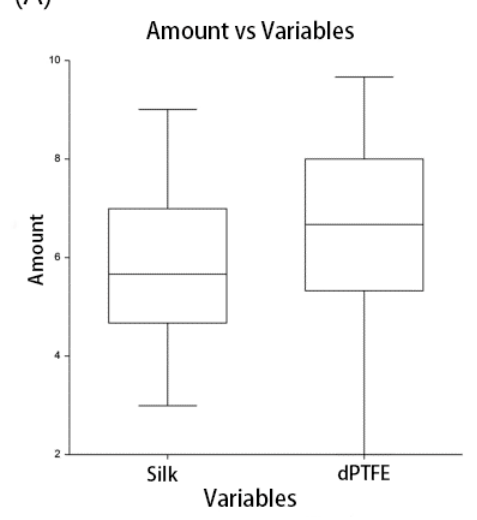

(B)

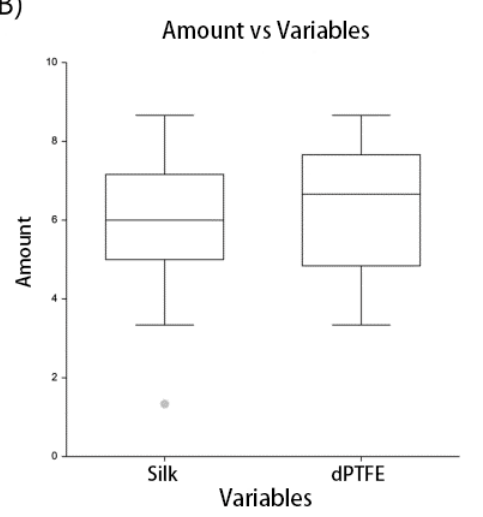

Figure 2. Mean and confidence interval of pocket depth (PD) reduction for both groups. (A) Mean and confidence interval for three months after surgery. The PD reduction in the silk mat group was not inferior to that of the dPTFE group ( $\left.p_{\text {non-inferiority }}<0.001\right)$. (B) Mean and confidence interval for six months after surgery. The PD reduction in the silk mat group was not inferior to that of the dPTFE group ( $\left.p_{\text {non-inferiority }}<0.001\right)$.

Mean PD reduction at T2 was $5.93 \pm 1.70 \mathrm{~mm}$ with silk mat versus $6.40 \pm 1.67 \mathrm{~mm}$ with dPTFE; the mean difference was $-0.47 \mathrm{~mm}$, the lower limit of one-sided $97.5 \% \mathrm{CI}:-1.42 \mathrm{~mm}$, pre-specified margin of non-inferiority $-2.8 \mathrm{~mm}, p_{\text {non-inferiority }}<0.001$ ). In patients undergoing GBR with silk mat 
for third-molar surgery, the results were non-inferior to GBR with dPTFE for PD reduction at T2 (Figure 2B).

\subsection{The Change of Pocket Depth and Clinical Attachment Level at Each Observation}

The difference in PD among observation points was statistically significant in both the silk mat group and the dPTFE group $(p<0.001)$. In a post hoc test, the PD at T0 was compared to the PD at T1; both the dPTFE group and the silk mat group showed significantly reduced PD (Table $1 ; p<0.001$ ). When the PD was compared at T0 to PD at T2, both the APTFE group and the silk mat group showed significantly reduced PD (Table $1 ; p<0.001)$.

Table 1. Summary of probing depth in patients who received membranes.

\begin{tabular}{ccccccc}
\hline \multirow{2}{*}{ Group } & \multirow{2}{*}{ T0 (mm) } & \multirow{2}{*}{ T1 $(\mathbf{m m})$} & \multirow{2}{*}{ T2 (mm) } & \multicolumn{3}{c}{$p$-Value } \\
\cline { 5 - 7 } & & & T0 to T1 & T0 to T2 & T1 to T2 \\
\hline dPTFE & $9.48 \pm 1.34$ & $3.11 \pm 1.11$ & $3.08 \pm 0.91$ & $<0.001$ & $<0.001$ & NS \\
\hline Silk mat & $9.27 \pm 1.29$ & $3.55 \pm 1.09$ & $3.33 \pm 0.86$ & $<0.001$ & $<0.001$ & NS \\
\hline
\end{tabular}

(T0: immediately after extraction, T1: three months after extraction, T2: six months after extraction, NS: not significant).

The difference in CAL among the observation points was statistically significant in both the silk mat group and the dPTFE group $(p<0.001)$. The mean gain of attachment at T1 was $4.84 \pm 1.62$ and $5.43 \pm 1.76 \mathrm{~mm}$ for the dPTFE and silk mat groups, respectively. In a post hoc test, CAL at T0 was compared to CAL at T1; both the dPTFE group and the silk mat group showed significantly improved CAL (Table 2; $p<0.001$ ). When CAL was compared at T0 to CAL at T2, both the dPTFE group and the silk mat group showed significantly improved CAL (Table 2; $p<0.001$ ). Mean gain of attachment at T2 was $5.23 \pm 1.46$ and $5.69 \pm 1.42 \mathrm{~mm}$ for dPTFE and silk mat groups, respectively.

Table 2. Summary of clinical attachment level in patients who received membranes.

\begin{tabular}{ccccccc}
\hline \multirow{2}{*}{ Group } & \multirow{2}{*}{ T0 (mm) } & \multirow{2}{*}{ T1 (mm) } & \multirow{2}{*}{ T2 (mm) } & \multicolumn{3}{c}{$p$-Value } \\
\cline { 5 - 7 } & & & T0 to T1 & T0 to T2 & T1 to T2 \\
\hline dPTFE & $8.01 \pm 1.14$ & $3.17 \pm 1.26$ & $2.79 \pm 0.89$ & $<0.001$ & $<0.001$ & NS \\
\hline Silk mat & $8.21 \pm 0.93$ & $2.79 \pm 1.29$ & $2.52 \pm 0.96$ & $<0.001$ & $<0.001$ & NS \\
\hline
\end{tabular}

(T0: immediate after extraction, T1: three months after extraction, T2: six months after extraction, NS: not significant).

\subsection{Membrane Application and Bone Regeneration after Mandibular Third-Molar Extraction}

BG in the dPTFE membrane group was $1.85 \pm 1.15$ and $3.56 \pm 3.30 \mathrm{~mm}$ at $\mathrm{T} 1$ and $\mathrm{T} 2$, respectively (Figure 3). BG in the silk mat group was $1.57 \pm 0.97$ and $3.61 \pm 3.33 \mathrm{~mm}$ at $\mathrm{T} 1$ and T2, respectively (Figure 3). When bone gain was compared between the groups, there was no significant difference in BG between the silk mat and dPTFE groups at T1 and T2 $(p>0.05)$.

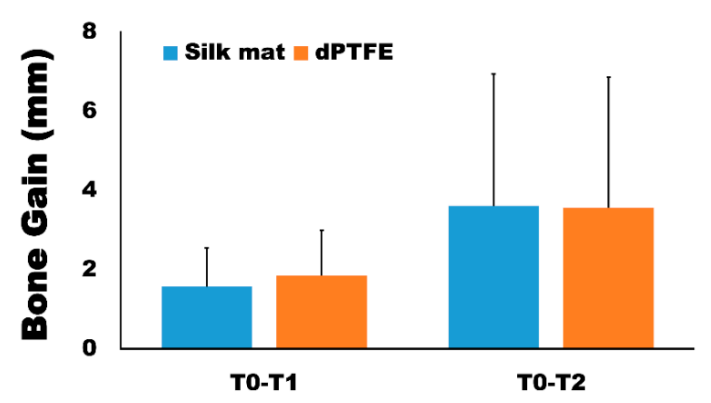

Figure 3. The amount of bone gain (BG) at three months (T1) and six months after tooth extraction (T2) compared to before tooth extraction (T0). There was no significant difference in BG between the silk mat and dPTFE groups at T1 and T2 $(p>0.05)$. 


\section{Discussion}

In this study, the influence on the periodontal health of the distal surface of the mandibular second molar after third-molar extraction was evaluated. The split-mouth, randomized clinical trial study demonstrated that there was no significant difference in PD, CAL, and BG between the dPTFE group and the silk mat group at T1 and T2 (Tables 1 and 2; $p>0.05$ ). This is the first study of GBR with silk mat in clinical trials.

The presence of a mandibular third molar is considered a threat to the periodontal health of the second molar [2]. Even a non-symptomatic mandibular third molar is recommended for surgical removal to prevent periodontal pathology in the second molar [2]. Age [8,13], sex [34], oral hygiene [20], and anatomical position [20] are considered predisposing factors for periodontal pathology. Accordingly, patients older than 26 years, or with more than $3 \mathrm{~mm}$ of an attachment level on the distal surface of the second molar are advised to have their mandibular third molar removed $[8,13]$. Approximately $40 \%$ of patients show increased bone loss after third-molar extraction among patients with more than $3 \mathrm{~mm}$ of bony defect in the distal surface of the mandibular second molar [34]. Accordingly, membrane application groups in this study included only patients with more than $3 \mathrm{~mm}$ of bony defect in the distal surface of the mandibular second molar preoperatively. To address deep mesioangular impaction, the preoperative PD should be at least $7.5 \mathrm{~mm}$ [14]. In this study, PD at T0 was $9.5 \pm 1.3 \mathrm{~mm}$ and $9.3 \pm 1.3 \mathrm{~mm}$ for the dPTFE group and the silk mat group, respectively (Table 1). To prevent postoperative periodontal pathology, flap design, suture technique, and periodontal care for the second molar were considered, but there is controversy about their effect on prevention [16]. GBR with a collagen membrane or PTFE membrane is a reliable method and beneficial in reducing PD compared with a non-regenerative/non-graft procedure [35]. There was no significant difference in PD reduction between the collagen membrane group and the PTFE membrane group after mandibular third-molar extraction [19].

In the case of an impacted third molar, surgical extraction only can increase alveolar bone height on the distal surface of the mandibular second molar [36]. PD at the distal surface of the mandibular second molar is reduced approximately $0.6 \mathrm{~mm}$ every three months after surgical removal of a mandibular third molar until PD becomes $2.6 \mathrm{~mm}$ [37]. The reduction in PD for the non-regenerative/non-graft procedure group was $1.3 \mathrm{~mm}$ at three months [14] and $1.93 \mathrm{~mm}$ at $12 \mathrm{months}$ [5]. When the PTFE group was compared with the non-regenerative/non-graft procedure group, a significant benefit from the PTFE membrane was demonstrated after mandibular third-molar extraction [20,35]. In cases of collagen membrane application, the amount of PD reduction at one year after extraction was $5.3 \pm 1.9 \mathrm{~mm}$ [19]. In this study, the amount of PD reduction at six months was $5.9 \pm 1.7 \mathrm{~mm}$ and $6.4 \pm 1.7 \mathrm{~mm}$ for the silk mat and dPTFE groups, respectively (Table 1). Mean gain of attachment at T2 was $5.23 \pm 1.46$ and $5.69 \pm 1.42 \mathrm{~mm}$ for the dPTFE and silk mat groups, respectively (Table 2). When GBR plus bone graft is compared to GBR only, there is little additional value in reducing PD after extraction [35].

Silk mat consists of fibroin and sericin protein. Silk fibroin has been widely studied for bone regeneration [28]. Sericin has been considered industrial waste, but its beneficial effect was illuminated recently $[38,39]$. Because sericin is hydrophilic protein and easily fragmented in aqueous solution, silk mat can be considered a drug carrier-releasing sericin [25]. All silk mats in this study came from the middle layer of the silkworm cocoon. In previous studies, the amount of fragmented sericin release was smallest in the middle layer $[25,26]$. The expression level of tumor necrosis factor-alpha (TNF- $\alpha$ ) from macrophages depends on the sericin concentration [25]. Activation of osteoblasts depends on the expression level of TNF- $\alpha$ from macrophages [25]. In comparative animal studies, silk mat has shown levels of bone formation similar to collagen and dPTFE [27]. In this clinical trial, GBR with silk mat showed levels of periodontal regeneration similar to GBR with dPTFE.

The limitation of this study was the lack of samples from a non-regenerative/non-graft procedure. Most previous studies demonstrated that the application of a membrane after mandibular third-molar extraction had significant benefit compared with a non-regenerative/non-graft procedure $[19,20,35]$. Some authors estimated that GBR in third-molar surgery offered little 
benefit over non-regenerative/non-graft procedures [33,40]. To be a successful GBR procedure in third-molar surgery, proper case selection is vital. Failure of bony healing in patients aged 20-29 years is $3 \%$, but, in those aged $30-50$ years, it is $21 \%$ [41]. In future studies, the samples for a non-regenerative/non-graft procedure should be collected prospectively and in a controlled manner. Because this was the first clinical trial for silk mat, the number of samples was limited; because no definite complication was associated with silk mat usage, larger-scale clinical trials for silk mat should be conducted.

\section{Conclusions}

The results and outcomes in patients undergoing GBR with silk mat for third-molar surgery were non-inferior to GBR with dPTFE for PD reduction at three and six months postoperatively. Both groups showed significant improvement in PD reduction and CAL gain compared with their preoperative level $(p<0.05)$.

Author Contributions: This study was designed by Y.-Y.J., B.-E.Y., and S.-G.K., B.-E.Y., J.-W.K., and J.-Y.K. did clinical trials and data analysis. J.O. collected untreated control samples and did radiogram analysis. J.-W.K., Y.-Y.J. and S.-G.K. wrote the manuscript and performed a critical review.

Funding: This randomized clinical trial research received funding from Spencer biomedical technology.

Acknowledgments: The authors thank Seung-Ho Shin and Ye-Jin Kang for their help in collecting samples in the control group. This work was carried out with the support of the Cooperative Research Program for Agriculture Science and Technology Development (Project no. PJ01313902) of the Rural Development Administration, Korea.

Conflicts of Interest: Spencer Biomedical technology, which manufactures TDI, provided the membrane for free and provided personnel support through an investigator-sponsored research agreement with B.-E.Y. The authors declare that the authors have no competing interests or other interests that might be perceived as influencing the results and/or discussion reported in this paper.

\section{References}

1. Schersten, E.; Lysell, L.; Rohlin, M. Prevalence of impacted third molars in dental students. Swed. Dent. J. 1989, 13, 7-13. [PubMed]

2. Nunn, M.E.; Fish, M.D.; Garcia, R.I.; Kaye, E.K.; Figueroa, R.; Gohel, A.; Ito, M.; Lee, H.J.; Williams, D.E.; Miyamoto, T. Retained asymptomatic third molars and risk for second molar pathology. J. Dent. Res. 2013, 92, 1095-1099. [CrossRef] [PubMed]

3. Kan, K.W.; Liu, J.K.; Lo, E.C.; Corbet, E.F.; Leung, W.K. Residual periodontal defects distal to the mandibular second molar 6-36 months after impacted third molar extraction. J. Clin. Periodontol. 2002, 29, 1004-1011. [CrossRef] [PubMed]

4. Kugelberg, C.F. Impacted lower third molars and periodontal health. An epidemiological, methodological, retrospective and prospective clinical, study. Swed. Dent. J. 1990, 68, 1-52.

5. Faria, A.I.; Gallas-Torreira, M.; Lopez-Raton, M. Mandibular second molar periodontal healing after impacted third molar extraction in young adults. J. Oral Maxillofac. Surg. 2012, 70, 2732-2741. [CrossRef] [PubMed]

6. Kim, S.Y.; Kim, Y.K.; Kim, H.S.; Yun, P.Y.; Kim, S.G.; Choi, Y.H. Extraction socket sealing using palatal gingival grafts and resorbable collagen membranes. Maxillofac. Plast. Reconstr. Surg. 2017, 39, 39. [CrossRef] [PubMed]

7. Kim, H.S.; Yun, P.Y.; Kim, Y.K. Intentional partial odontectomy-a long-term follow-up study. Maxillofac. Plast. Reconstr. Surg. 2017, 39, 29. [CrossRef]

8. Kugelberg, C.F.; Ahlstrom, U.; Ericson, S.; Hugoson, A.; Kvint, S. Periodontal healing after impacted lower third molar surgery in adolescents and adults. A prospective study. Int. J. Oral Maxillofac. Surg. 1991, 20, 18-24. [CrossRef]

9. NIH consensus development conference for removal of third molars. J. Oral Surg. 1980, 38, $235-236$.

10. Karapataki, S.; Hugoson, A.; Kugelberg, C.F. Healing following GTR treatment of bone defects distal to mandibular 2nd molars after surgical removal of impacted 3rd molars. J. Clin. Periodontol. 2000, 27, 325-332. [CrossRef] 
11. Blakey, G.H.; Parker, D.W.; Hull, D.J.; White, R.P., Jr.; Offenbacher, S.; Phillips, C.; Haug, R.H. Impact of removal of asymptomatic third molars on periodontal pathology. J. Oral Maxillofac. Surg. 2009, 67, 245-250. [CrossRef]

12. Ramirez, V.; Marro, P.; Lopez, R. Effect of mechanical debridement on distal periodontal aspects of second molars after the extraction of third molars: A systematic review. J. Periodontol. 2012, 83, 595-601. [CrossRef]

13. Dodson, T.B. Is there a role for reconstructive techniques to prevent periodontal defects after third molar surgery? J. Oral Maxillofac. Surg. 2005, 63, 891-896. [CrossRef]

14. Kumar, N.; Prasad, K.; Ramanujam, L.; Ranganath, K.; Dexith, J.; Chauhan, A. Evaluation of treatment outcome after impacted mandibular third molar surgery with the use of autologous platelet-rich fibrin: A randomized controlled clinical study. J. Oral Maxillofac. Surg. 2015, 73, 1042-1049. [CrossRef]

15. Kugelberg, C.F.; Ahlstrom, U.; Ericson, S.; Hugoson, A.; Thilander, H. The influence of anatomical, pathophysiological and other factors on periodontal healing after impacted lower third molar surgery: A multiple regression analysis. J. Clin. Periodontol. 1991, 18, 37-43. [CrossRef]

16. Chen, Y.W.; Lee, C.T.; Hum, L.; Chuang, S.K. Effect of flap design on periodontal healing after impacted third molar extraction: A systematic review and meta-analysis. Int. J. Oral Maxillofac. Ssurg. 2017, 46, 363-372. [CrossRef] [PubMed]

17. Lee, C.T.; Hum, L.; Chen, Y.W. The effect of regenerative periodontal therapy in preventing periodontal defects after the extraction of third molars: A systematic review and meta-analysis. J. Am. Dent. Assoc. 2016, 147, 709-719.e4. [CrossRef]

18. DurmuSlar, M.C.; Alpaslan, C.; Alpaslan, G.; Cakir, M. Clinical and radiographic evaluation of the efficacy of platelet-rich plasma combined with hydroxyapatite bone graft substitutes in the treatment of intra-bony defects in maxillofacial region. Acta Odontol. Scand. 2014, 72, 948-953. [CrossRef]

19. Karapataki, S.; Hugoson, A.; Falk, H.; Laurell, L.; Kugelberg, C.F. Healing following GTR treatment of intrabony defects distal to mandibular 2nd molars using resorbable and non-resorbable barriers. J. Clin. Periodontol. 2000, 27, 333-340. [CrossRef]

20. Pecora, G.; Celletti, R.; Davarpanoh, M.; Covani, U.; Etienne, D. The effects of guided tissue regeneration on healing after impacted mandibular third-molar surgery: 1-year results. Int. J. Periodontics Restor. Dent. 1993, 13, 396-407.

21. Barboza, E.P.; Stutz, B.; Ferreira, V.F.; Carvalho, W. Guided bone regeneration using nonexpanded polytetrafluoroethylene membranes in preparation for dental implant placements-A report of 420 cases. Implant Dent. 2010, 19, 2-7. [CrossRef] [PubMed]

22. Barber, H.D.; Lignelli, J.; Smith, B.M.; Bartee, B.K. Using a dense PTFE membrane without primary closure to achieve bone and tissue regeneration. J. Oral Maxillofac. Surg. 2007, 65, 748-752. [CrossRef]

23. Yoo, C.K.; Jeon, J.Y.; Kim, Y.J.; Kim, S.G.; Hwang, K.G. Cell attachment and proliferation of osteoblast-like MG63 cells on silk fibroin membrane for guided bone regeneration. Maxillofac. Plast. Reconstr. Surg. 2016, 38, 17. [CrossRef] [PubMed]

24. Kim, S.G.; Kim, M.K.; Kweon, H.; Jo, Y.Y.; Lee, K.G.; Lee, J.K. Comparison of unprocessed silk cocoon and silk cocoon middle layer membranes for guided bone regeneration. Maxillofac. Plast. Reconstr. Surg. 2016, 38, 11. [CrossRef] [PubMed]

25. Jo, Y.Y.; Kweon, H.; Kim, D.W.; Baek, K.; Kim, M.K.; Kim, S.G.; Chae, W.S.; Choi, J.Y.; Rotaru, H. Bone regeneration is associated with the concentration of tumour necrosis factor-alpha induced by sericin released from a silk mat. Sci. Rep. 2017, 7, 15589. [CrossRef]

26. Kweon, H.; Jo, Y.-Y.; Seok, H.; Kim, S.-G.; Chae, W.-S.; Sapru, S.; Kundu, S.C.; Kim, D.-W.; Park, N.-R.; $\mathrm{Che}, \mathrm{X}$; et al. In vivo bone regeneration ability of different layers of natural silk cocoon processed using an eco-friendly method. Macromol. Res. 2017, 25, 806-816. [CrossRef]

27. Ha, Y.-Y.; Park, Y.-W.; Kweon, H.; Jo, Y.-Y.; Kim, S.-G. Comparison of the physical properties and in vivo bioactivities of silkworm-cocoon-derived silk membrane, collagen membrane, and polytetrafluoroethylene membrane for guided bone regeneration. Macromol. Res. 2014, 22, 1018-1023. [CrossRef]

28. Song, J.Y.; Kim, S.G.; Lee, J.W.; Chae, W.S.; Kweon, H.; Jo, Y.Y.; Lee, K.G.; Lee, Y.C.; Choi, J.Y.; Kim, J.Y. Accelerated healing with the use of a silk fibroin membrane for the guided bone regeneration technique. Oral Surg. Oral Med. Oral Pathol. Oral Radiol. Endod. 2011, 112, e26-e33. [CrossRef] [PubMed] 
29. Corinaldesi, G.; Lizio, G.; Badiali, G.; Morselli-Labate, A.M.; Marchetti, C. Treatment of intrabony defects after impacted mandibular third molar removal with bioabsorbable and non-resorbable membranes. J. Periodontol. 2011, 82, 1404-1413. [CrossRef] [PubMed]

30. Sammartino, G.; Tia, M.; Bucci, T.; Wang, H.L. Prevention of mandibular third molar extraction-associated periodontal defects: A comparative study. J. Periodontol. 2009, 80, 389-396. [CrossRef]

31. Julious, S.A. Sample sizes for clinical trials with normal data. Stat. Med. 2004, 23, 1921-1986. [CrossRef]

32. Sealed Envelope Ltd. Power Calculator for Continuous Outcome Non-Inferiority Trial. 2012. Available online: https:/ / www.sealedenvelope.com/power/continuous-noninferior/ (accessed on 20 August 2016).

33. Oxford, G.E.; Quintero, G.; Stuller, C.B.; Gher, M.E. Treatment of 3rd molar-induced periodontal defects with guided tissue regeneration. J. Clin. Periodontol. 1997, 24, 464-469. [CrossRef] [PubMed]

34. Kugelberg, C.F.; Ahlstrom, U.; Ericson, S.; Hugoson, A. Periodontal healing after impacted lower third molar surgery. A retrospective study. Int. J. Oral Surg. 1985, 14, 29-40. [CrossRef]

35. Barbato, L.; Kalemaj, Z.; Buti, J.; Baccini, M.; La Marca, M.; Duvina, M.; Tonelli, P. Effect of Surgical Intervention for Removal of Mandibular Third Molar on Periodontal Healing of Adjacent Mandibular Second Molar: A Systematic Review and Bayesian Network Meta-Analysis. J. Periodontol. 2016, 87, 291-302. [CrossRef] [PubMed]

36. Krausz, A.A.; Machtei, E.E.; Peled, M. Effects of lower third molar extraction on attachment level and alveolar bone height of the adjacent second molar. Int. J. Oral Maxillofac. Surg. 2005, 34, 756-760. [CrossRef] [PubMed]

37. Montero, J.; Mazzaglia, G. Effect of removing an impacted mandibular third molar on the periodontal status of the mandibular second molar. J. Oral Maxillofac. Surg. 2011, 69, 2691-2697. [CrossRef]

38. Kim, J.W.; Jo, Y.Y.; Kweon, H.Y.; Kim, D.W.; Kim, S.G. The effects of proteins released from silk mat layers on macrophages. Maxillofac. Plast. Reconstr. Surg. 2018, 40, 10. [CrossRef]

39. Wang, Z.; Zhang, Y.; Zhang, J.; Huang, L.; Liu, J.; Li, Y.; Zhang, G.; Kundu, S.C.; Wang, L. Exploring natural silk protein sericin for regenerative medicine: An injectable, photoluminescent, cell-adhesive 3D hydrogel. Sci. Rep. 2014, 4, 7064. [CrossRef]

40. Dodson, T.B. Management of mandibular third molar extraction sites to prevent periodontal defects. J. Oral Maxillofac. Surg. 2004, 62, 1213-1224. [CrossRef]

41. Marmary, Y.; Brayer, L.; Tzukert, A.; Feller, L. Alveolar bone repair following extraction of impacted mandibular third molars. Oral Surg. Oral Med. Oral Pathol. 1986, 61, 324-326. [CrossRef] 